\title{
Two Cyc2CL transcripts (Cyc2CL-1 and Cyc2CL-2) may play key roles in the petal and stamen development of ray florets in chrysanthemum
}

\author{
Hua Liu' ${ }^{1}$, Ming Sun ${ }^{1}$, Huitang Pan ${ }^{1}$, Tangren Cheng ${ }^{1}$, Jia Wang ${ }^{1}$ and Qixiang Zhang ${ }^{1,2^{*}}$
}

\begin{abstract}
Background: Chrysanthemum morifolium is one of the most popular ornamental crops. The capitulum, which is the main ornamental part of chrysanthemum plants, consists of ligulate marginal ray florets, an attractive corolla (petals), and radially hermaphroditic disc florets, but no stamens. In Asteraceae species, the zygomorphic ray florets evolved from the actinomorphic disc florets. During this process, the zygomorphic ligulate corolla arose and the stamens were aborted. Although molecular genetic research has clarified ray floret development to some extent, the precise molecular mechanism underlying ray floret development in chrysanthemum remained unclear.

Results: A CYC2-like gene, Cyc2CL, was cloned from C. morifolium 'Fenditan'. Subsequent analyses revealed that the alternative splicing of $\mathrm{CyC} 2 \mathrm{CL}$, which occurred in the flower differentiation stage, resulted in the production of Cyc2CL-1 and Cyc2CL-2 in the apical buds. Prior to this stage, only Cyc2CL-1 was produced in the apical buds. A fluorescence in situ hybridization analysis of labeled Cyc2CL-1 and Cyc2CL-2 RNA indicated that CyC2CL-2 was first expressed in the involucre tissue during the final involucre differentiation stage, but was subsequently expressed in the receptacle and floret primordia as the floral bud differentiation stage progressed. Moreover, Cyc2CL-2 was highly expressed in the inflorescence tissue during the corolla formation stage, and the expression remained high until the end of the floral bud differentiation stage. Furthermore, the overexpression of $\mathrm{Cyc} 2 \mathrm{CL}-1$ and $\mathrm{CyC} 2 \mathrm{CL}-2$ in transgenic Arabidopsis inhibited stamen and petal development. Therefore, both Cyc2CL-1 and Cyc2CL-2 encode candidate regulators of petal development and stamen abortion and are important for the ray floret development in chrysanthemum.
\end{abstract}

\footnotetext{
* Correspondence: zqxbjfu@126.com

'Beijing Key Laboratory of Ornamental Plants Germplasm Innovation \& Molecular Breeding, National Engineering Research Center for Floriculture, Beijing Laboratory of Urban and Rural Ecological Environment, Engineering Research Center of Landscape Environment of Ministry of Education, Key Laboratory of Genetics and Breeding in Forest Trees and Ornamental Plants of Ministry of Education, School of Landscape Architecture, Beijing Forestry University, Beijing 100083, China

${ }^{2}$ Beijing Advanced Innovation Center for Tree Breeding by Molecular Design, Beijing Forestry University, Beijing 100083, China
}

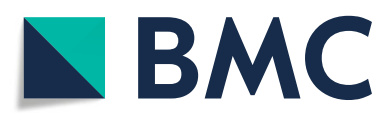

(c) The Author(s). 2021 Open Access This article is licensed under a Creative Commons Attribution 4.0 International License, which permits use, sharing, adaptation, distribution and reproduction in any medium or format, as long as you give appropriate credit to the original author(s) and the source, provide a link to the Creative Commons licence, and indicate if changes were made. The images or other third party material in this article are included in the article's Creative Commons licence, unless indicated otherwise in a credit line to the material. If material is not included in the article's Creative Commons licence and your intended use is not permitted by statutory regulation or exceeds the permitted use, you will need to obtain permission directly from the copyright holder. To view a copy of this licence, visit http://creativecommons.org/licenses/by/4.0/. The Creative Commons Public Domain Dedication waiver (http://creativecommons.org/publicdomain/zero/1.0/) applies to the data made available in this article, unless otherwise stated in a credit line to the data. 
(Continued from previous page)

Conclusion: In this study, we characterized the alternatively spliced transcripts of the CYC2-like gene that differ subtly regarding expression and function. The data presented herein will be useful for clarifying the regulatory mechanisms associated with the CYC2-like gene and may also be important for identifying the key genes and molecular mechanisms controlling the development of ray florets in chrysanthemum.

Keywords: Chrysanthemum morifolium, Ray florets, Disc florets, CYC2-like genes, Stamen abortion, Alternative splicing

\section{Background}

Asteraceae is the largest family of flowering plants, and it belongs to the euasterids II clade of the core eudicots. The unique head-like inflorescence of Asteraceae species, known as a capitulum, often consists of the following two morphologically and functionally differentiated florets: bilateral (zygomorphic) ray florets and radial (actinomorphic) disc florets [18]. The marginal ray florets are ligulate and female, with an attractive corolla (petals), but no stamens. The inner disc florets with fertile pollen grains are radially pentamerous and hermaphroditic. In Asteraceae species, zygomorphic ray florets evolved from the actinomorphic disc florets [41]. In angiosperms, the transition to bilateral floral symmetry is considered to represent one of three critical evolutionary events, and is related to the evolution of specialized flower-pollinator interactions that contributed to the diversification of flowering plant lineages $[1,12,20]$.

The development of the zygomorphic female ray floret was an important event associated with the evolutionary success of the capitulum in Asteraceae species because the ray floret is highly attractive to pollinators and can significantly improve the outcrossing rate [44]. The following two fundamental changes occurred during the development of the zygomorphic female ray floret: the zygomorphic ligulate corolla arose and the stamens were aborted. Many recent phylogenetic and biological studies have focused on this trait.

In Antirrhinum majus (Lamiales), the TCP transcription factors CYCLOIDEA (CYC) and DICHOTOMA (DICH) were isolated and characterized as key regulators of floral zygomorphy [33]. Several CYC-like TCP-encoding genes have been identified in Asteraceae species, and the CYCLOIDEA/TEOSINTE BRANCHED1 (CYC/TB1)-like subfamily was classified into the following three $C Y C$ clades: $C Y C 1, C Y C 2$, and $C Y C 3$, of which $C Y C 2$ clade genes underwent multiple duplication events, resulting in the functional diversification of these genes within the Asteraceae lineage [43]. The 10 CYC/TB1-like genes identified in sunflower belong to three distinct clades $(C Y C 1$, $C Y C 2$, and $C Y C 3$ ), which is consistent with what has been determined for other eudicot species. Previous studies proposed that gene duplication and functional divergence have greatly facilitated the diversification of the sunflower
CYC gene family $[3,5]$. Additionally, a phylogenetic analysis of $C Y C$-like genes revealed that different paralogs of these genes may have been independently recruited to mediate the zygomorphy in different Asteraceae species [7]. In Gerbera hybrida, the CYC-like homolog GhCYC2 is specifically expressed in the marginal zygomorphic ray florets, but not in the center-most actinomorphic disc flowers. The overexpression of $G h C Y C 2$ results in the production of disc flowers that are morphologically similar to ray flowers. Moreover, GhCYC2 is reportedly important for the differentiation of flower types in G. hybrida [2]. In Senecio species, RAY1 is important for regulating floret identity (i.e., ray or disc florets), whereas RAY2 promotes the ventral identity of ray florets. The RAY1 and $R A Y 2$ genes belong to a subfamily of TCP genes, and RAY2 may be an ortholog of GhCYC2 in G. hybrida [34]. In a previous study of sunflower mutants, a CYC-like gene, $\mathrm{HaCYC} 2 c$, was expressed throughout the inflorescence, and disc florets developed bilateral symmetry [7]. Therefore, in Asteraceae species, some $C Y C 2$ clade genes that are specifically expressed in ray florets determine floret identity (i.e., ray or disc florets). Examples include GhCYC2 in G. hybrida, HaCYC2d and HaCYC2c in sunflower, and RAY1 and RAY2 in Senecio vulgaris.

In an earlier investigation, tissue slices were analyzed to study early stamen development and the subsequent abortion in Gerbera species. The results indicated that in the early stages, the stamen primordia in ray and disc florets develop similarly, but the development of the stamen primordium in ray florets subsequently starts to lag behind the corresponding development in disc florets. Additionally, the stamens of ray florets are gradually aborted [29]. However, little is known about the molecular mechanisms responsible for stamen abortion in ray florets.

The alternative splicing (AS) of precursor mRNAs (premRNAs) enables the same gene to generate multiple transcripts that may encode various protein isoforms. Alternative splicing has profound functional consequences because of the resulting changes to protein production. Moreover, AS is broadly useful for enhancing molecular versatility. Specifically, it is a key gene regulatory process that influences almost all analyzed biological functions. Additionally, AS increases the coding potential of genomes, and represents an important post-transcriptional regulatory mechanism for increasing 
the proteomic diversity and functional complexity of higher eukaryotes. Furthermore, AS is common in plants [4, 39]. However, whether $C Y C 2$-like genes are affected by AS remains unknown.

Chrysanthemum morifolium, which is one of the most popular ornamental crops, is cultivated worldwide [19, 40]. The main ornamental part of C. morifolium plants is the capitulum, and its typical structure contains morphologically distinct ray and disc florets (Supplemental Figure S1). Ray florets, which are ligulate and zygomorphic, have a showy corolla (petals) and lack stamens. Their primary function is to attract pollinators. The central disc florets, which are radially symmetrical and hermaphroditic, have fertile pollen grains and are mainly required for reproduction [31]. In this study, a $C Y C 2$ like gene, $C y c 2 C L$, was cloned from $C$. morifolium 'Fenditan'. The AS of $C y c 2 C L$ resulted in two distinct transcripts $(C y c 2 C L-1$ and $C y c 2 C L-2)$, which were produced in the apical buds after the flower differentiation stage was initiated. Prior to this stage, only $C y c 2 C L-1$ was produced in apical buds. Additionally, $C y c 2 C L-2$ was first expressed in the involucre tissue during the final involucre differentiation stage. As the floral bud differentiation stage proceeded, $C y c 2 C L-2$ was expressed in the receptacle and floret primordia. Studies involving transgenic Arabidopsis plants revealed that the overexpression of $C y c 2 C L-1$ and $C y c 2 C L-2$ can inhibit the development of stamens and petals. Therefore, Cyc2CL may play a key role in controlling the stamen abortion and petal development of ray florets and is likely a crucial regulator of chrysanthemum ray floret development. The results of this study are important for clarifying the molecular mechanisms underlying ray floret development in chrysanthemum and may be useful for identifying important candidate genes for the breeding of chrysanthemum and related species.

\section{Results}

Isolation of chrysanthemum CYC homologs

We isolated the pre-mRNA sequences (1146 bp) and the two alternatively spliced transcripts $(C y c 2 C L-1$ and Cyc2CL-2) of the CYC-like gene Cyc2CL (Fig. 1). The full-length $C y c 2 C L-1$ and $C y c 2 C L-2$ genomic sequences were also cloned (Supplemental Figure S2). As shown in Fig. $1 b$, the splice variants are derived from a pre-mRNA transcript and alternative splicing produces two types of mRNA. The Cyc2CL-1 exon sequences contained 819 bp. Regarding $C y c 2 C L-2$, the first exon comprised 795 bp and was similar to the $C y c 2 C L-1$ exon, whereas the second exon consisted of $105 \mathrm{bp}$, which matched part of the $C y c 2 C L-1$ intron. The $C y c 2 C L-2$ exons were separated by an intron sequence (246 bp). Thus, Cyc $2 C L-1$ and $C y c 2 C L-2$ shared partly similar exon sequences, but had diverse intron sequences. The splice sites of the Cyc2CL-2 exons and intron are consistent with the canonical GT-AG splice sites, whereas the splice sites of the $C y c 2 C L-1$ exon and intron are non-canonical sequences [38]. The $C y c 2 C L-1$ and $C y c 2 C L-2$ coding sequences were 819 and $900 \mathrm{bp}$, respectively. The encoded Cyc2CL-1 and Cyc2CL-2 amino acid sequences were 89\% similar (Fig. 1c). The deduced Cyc2CL-1 and Cyc2CL-2 amino acid sequences included the conserved TCP and R domains typical of CYC/TB1 subfamily members (Figs. 2 and 3). During phylogenetic analyses, $C y c 2 C L-1$ and $C y c 2 C L-2$ were clustered with the other CYC2 members in $C$. morifolium as well as with the CYC2-like genes of Helianthus annuus, G. hybrida, and $S$. vulgaris, implying there may have been several $C Y C 2$

\begin{abstract}
ATGITTCTTCAAACCCCTTTCCAGAGTTCTCCCATCCCCTAAGTCCCCCTTCCTCTAATTATACTTGAT CTTGAAAAGACTATTITAACACTGGCGCGTTATCTCCACCGACGGCTATTITCATGGCTACAACGCTCTI ACTCCTCTACCATTCATGGAGGATCTTAATACAATTAGTCAAGATTTTCTAGTCAACAGCATCAGTTTTCTG ATGTTCAAAGGTTGGATCTCCTGAAGATGTTGATGATCTCTAAGGGTAGTAATTTCTAGCTCGAAGTCAA AGAAGAAAACTGACAAATCCAAGAAAGATGGACACAGTAAGATTAACGCAGCTCAAGGCCCTCGGGATC GAAGGGTGAGATGICCATTGAGATCTCAAGAAAGTCITIGTCTTCAAGACTGCTAGGIITGACAAA GCAAGCAAAACCCTTGATTGGCTATTTAGTAAATCGAAGAACGCGATTAAGGAGCTGGTTGAAGAAATAA ACCACAGCTCATCTICCACTGTGACTGATCAATCTAAGCTAATTTTCTTGAAGCCATTAAAGGAGGATCAG ATGCAGATAAAGAGAAAAGAAGTCAGCAATCAAGTATGGTGATGTCAAAAGGAGGAAATGACACCAA AATCAAAAGCTGTTGTTCAAGAGAATCTAGCAAGGACCAGTCTAGGGCCATGGCAAGAGCGAGAGCAC GAGAAGGACTAGAGAAAAGATGAATACCAAAACAGCTGATGATGATTTGAAGACATTACTTCATGATGA IITTGATTACCATG'GATGCTATTGCGCCTATATCTAĞTTGTTTAAGTCTAACTGAATCAAAAATGATAATAAGT ACTGAACTGTTTCATTGAATTTCTIATAGTTTIAATTAATCCGGAAAAATACGCCAATTTACCAAAGTTIATA GCACGGATAAGCAGCTTGATGATTATGCGATCAAATGATTTCAAAAACACACATGCAGTACTAGCTGATATA CGTGATTTTACTAACATTTATCTGTTTTCTTATTTGACAĞ̈AACTTGGAAAGAAATGCAGGAGAAATTAATAG GGCTATTTIGACAGCCAGCAGTACTGACCACTTCTGGGCAGGAATAATGGTGGACCTGGACTGATGTTG
\end{abstract} TAA

\section{A}

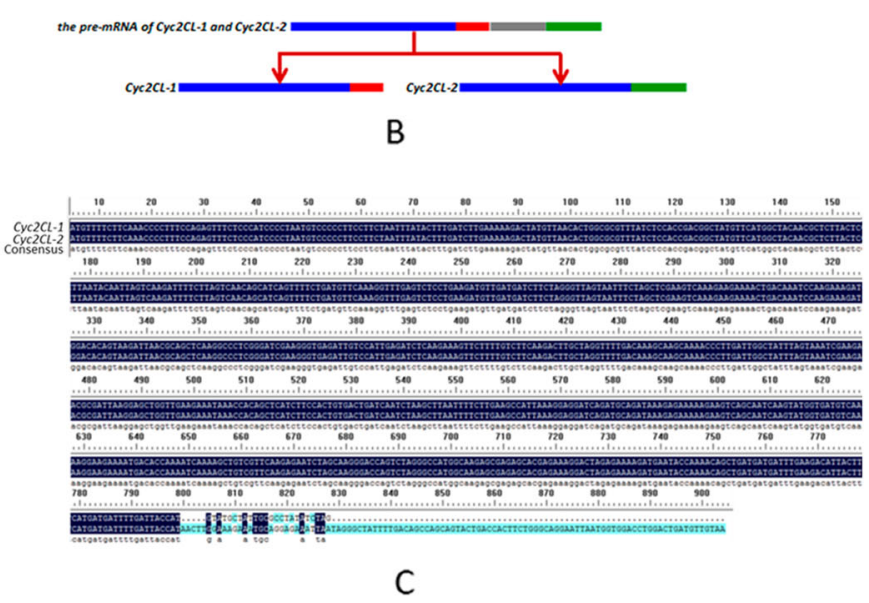

C

Fig. 1 Alternative splicing of $C y c 2 C L$ in C. morifolium. a Cyc2CL-1 and Cyc2CL-2 pre-mRNA sequences. The Cyc2CL-1 and Cyc2CL-2 exons are indicated with solid and dashed lines, respectively. Triangles indicate the splice sites. b Alternative splicing of Cyc2CL in C. morifolium. The blue bar indicates the common exon sequences of $\mathrm{Cyc} 2 \mathrm{CL}-1$ and $\mathrm{CyC} 2 \mathrm{CL}-2$. The red and green bars indicate the exon sequences of $\mathrm{Cyc} 2 \mathrm{CL}-1$ and Cyc2 $C L-2$, respectively. The gray bar indicates the intron sequences. $c$ Alignment of the Cyc2CL-1 and Cyc2CL-2 mRNA sequences 


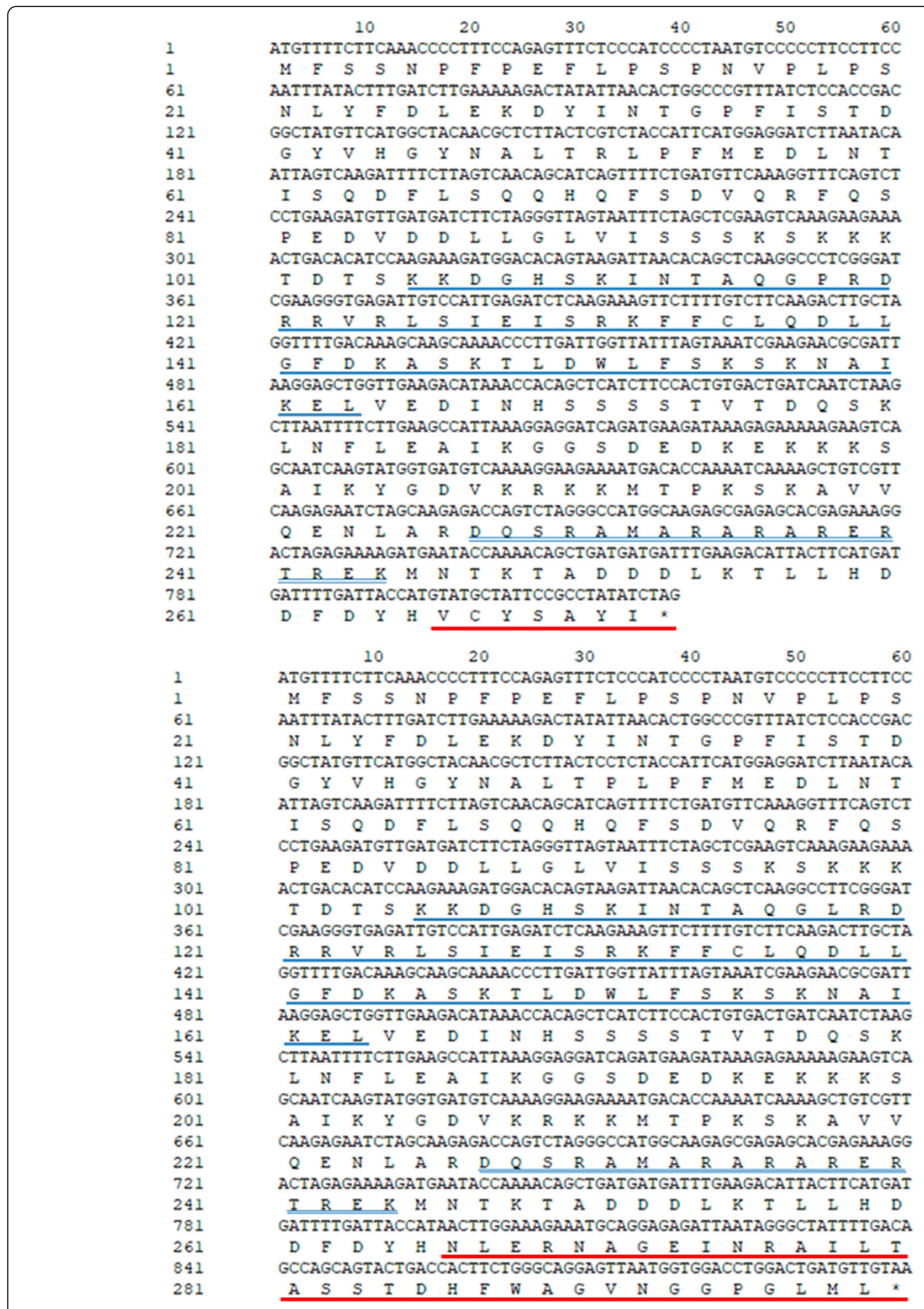

Fig. 2 Coding sequences and deduced amino acid sequences of $C y C 2 C L-1$ and $C y C 2 C L-2$. The blue single and double underlines indicate the TCP and $\mathrm{R}$ domains, respectively. The differences in the alternatively spliced transcripts are underlined in red 


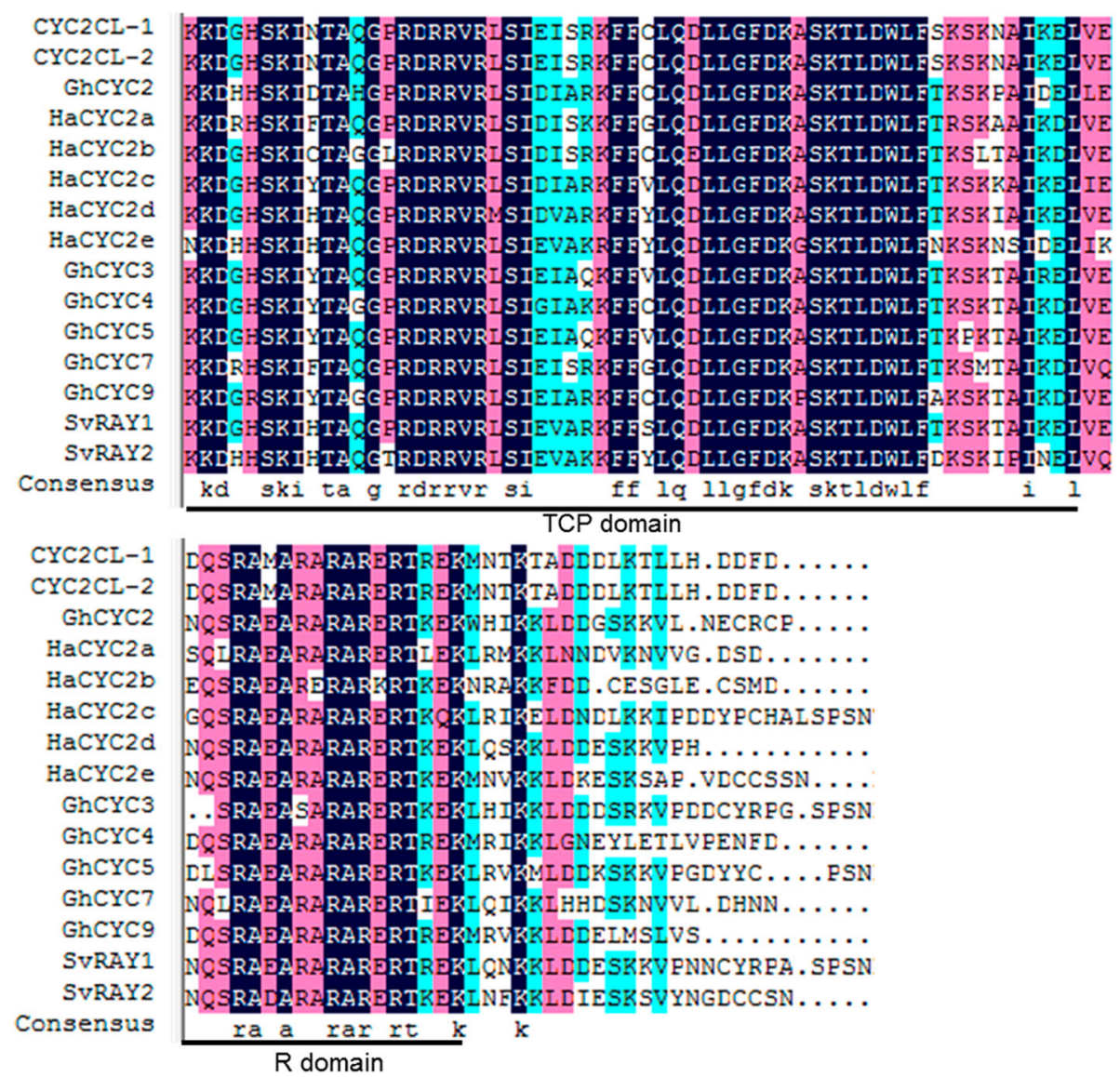

Fig. 3 Multiple sequence alignment of CYC proteins from C. morifolium and other species. The TCP and R domains are indicated by lines below the aligned sequences. The Genbank accession numbers for the genes in the sequence alignment are as follows: CYC2CL-1 (Chrysanthemum morifolium, AIU94285.1), CYC2CL-1 (C. morifolium, BAC11907.1), GhCYC2 (Gerbera hybrida, ACC54347.1), HaCYC2a (Helianthus annuus, ABV26442.1), HaCYC2b (H. annuus, ABV26443.1), HaCYC2C (H. annuus, ABV26444.1), HaCYC2d (H. annuus, ABV26445.1), HaCYC2e (H. annuus, ABV26446.1), GhCYC3 (G. hybrida, ACC54348.1), GhCYC4 (G. hybrida, ACC54349.1), GhCYC5 (G. hybrida, AEX07362.1), GhCYC7 (G. hybrida, AEX07364.1), GhCYC9 (G. hybrida, AEX07366.1), SVRAY1 (Senecio vulgaris, ACJ71723.1), and SVRAY2 (S. vulgaris, ACJ71727.1)

subclade gene duplication events in Asteraceae species (Fig. 4).

\section{Expression analyses of chrysanthemum CYC homologs}

A quantitative real-time polymerase chain reaction (qRT-PCR) assay was conducted to analyze the expression levels of $C Y C$-like genes in chrysanthemum floral parts. Relatively low $C y c 2 C L-1$ expression levels were detected in the leaves and vegetative buds, whereas $C y c 2 C L-2$ expression was undetectable in the vegetative buds (Fig. 5). During chrysanthemum bud development, the $C y c 2 C L-1$ and $C y c 2 C L-2$ expression levels tended to increase. Additionally, $C y c 2 C L-1$ and $C y c 2 C L-2$ were highly expressed in ray florets, but were expressed at low levels in disc florets. These results implied that $\mathrm{Cyc} 2 \mathrm{CL}-$ 2 is not expressed in the vegetative buds, but is expressed when floral bud differentiation is initiated. An analysis of gene expression patterns in various floral tissues revealed that $C y c 2 C L-1$ was highly expressed in the ray floret corolla, involucral bract, and receptacle, and relatively highly expressed in the pistil (stigma, style, and ovary) (Fig. 6). In contrast, Cyc2CL-2 was mainly expressed in the ray floret corolla. Both $C y c 2 C L-1$ and Cyc2CL-2 were expressed at extremely low levels in the disc floret tissues, including the corolla, stamen, and pistil (stigma, style, and ovary) (Fig. 6). Thus, both $C y c 2 C L$ 1 and $C y c 2 C L-2$ were mainly expressed in floral reproductive organs and weakly expressed in vegetative organs. This is consistent with the results of an earlier investigation on Gerbera species and sunflower [2].

A fluorescence in situ hybridization (FISH) analysis of labeled $C y c 2 C L-1$ and $C y c 2 C L-2$ RNA indicated that Cyc2CL-2 was expressed at low levels in the involucre tissue during the final involucre differentiation stage (Fig. 7b, d). During the floret primordia differentiation stage, $C y c 2 C L-2$ was expressed in multiple tissues, including the involucre, receptacle, and floret primordia. During the corolla formation stage, which follows the 


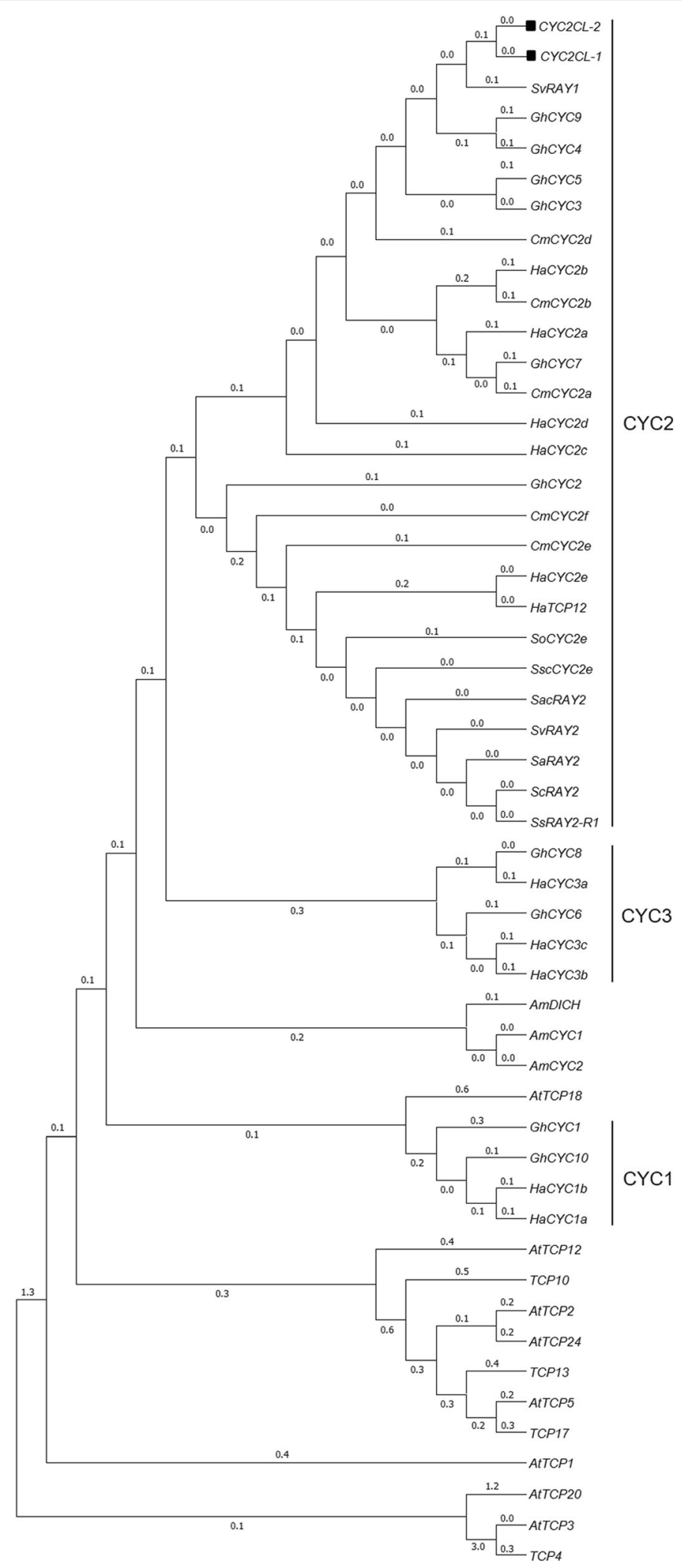

Fig. 4 (See legend on next page.) 
(See figure on previous page.)

Fig. 4 Phylogenetic tree of CYC genes from C. morifolium and other species. The Genbank accession numbers for the genes used to construct the phylogenetic tree are as follows: GhCYC5: AEX07362.1, HaCYC2C: ABV26444.1, GhCYC3: ACC54348.1, GhCYC7: AEX07364.1, HaCYC2a: ABV26442.1, SVRAY1: ACJ71723.1, HaCYC2d: ABV26445.1, GhCYC9: AEX07366.1, GhCYC4: ACC54349.1, GhCYC2: ACC54347.1, SvRAY2: ACJ71727.1, HaCYC2e: ABV26446.1, HaCYC2b: ABV26443.1, CYC2CL-1: CAD23438.1, CYC2CL-2: AAK21248.1, CmCYC2a: KU595430.1, CmCYC2b: KU595431.1, CmCYC2d: KU595426.1, CmCYC2e: KU595427.1, CmCYC2f: KU595429.1, GhCYC10: AEX07367.1, GhCYC1: ACC54346.1, HaCYC1b: ABV26441.1, HaCYC1a: ABV26440.1, HaCYC3a: ABV26447.1, GhCYC8: AEX07365.1, GhCYC6: AEF59025.1, GhCYC8: AEX07365.1, GhCYC6: AEX07363.1, HaCYC3c: ABV26449.1, HaCYC36: ABV26448.1, AmDICH: AAF12817.1, AmCYC1: Q9SBV9.1, AmCYC2: O49250.1, AtTCP3: AEE32909.1, AtTCP5: AED97405.1, AtTCP2: AEE84040.1, AtTCP24: AEE31193.1, AtTCP20: AEE77254.1, AtTCP18: OAP04988.1, AtTCP1: OAP12772.1, AtTCP12: AEE34841.1, AtTCP4: EU550941.1, AtTCP10: EU550953.1, AtTCP13: XP_020886906.1, AtTCP17: NM_001342977, SscCYC2e: MG593448.1, SoCYC2e: MG593440.1, ScRAY2:JQ351921.1, SacRAY2: JQ351929.1, SaRAY2: JQ351911.1, SsRAY2-R1: FJ356704.1, and HaTCP12: XP_022034966.1

floral bud differentiation stage, Cyc2CL-2 was highly expressed in the inflorescence tissue. Fluorescence was undetectable in the FISH assay negative controls, in which the sense probes for $C y c 2 C L-1$ and $C y c 2 C L-2$ RNA were used (Supplemental Figure 3). Thus, Cyc2CL2 was initially expressed in the involucre tissue, but was also expressed in other tissues during the floral bud differentiation stage. The qRT-PCR data confirmed that before the floral bud differentiation stage, $C y c 2 C L-2$ was not expressed. However, unlike Cyc2CL-2, Cyc2CL-1 was expressed in all inflorescence tissues at relatively high levels.

\section{Morphological effects of chrysanthemum CYC homologs in transgenic Arabidopsis}

Two constructs respectively expressing $C y c 2 C L-1$ and Cyc2CL-2 under the control of the $35 \mathrm{~S}$ promoter (35S:: Cyc2CL-1 and 35S::Cyc2CL-2) were inserted into Arabidopsis according to the floral-dip method, resulting in
42 and 48 independent lines of 35S::Cyc2CL-1 and 35S:: Cyc2CL-2 plants, respectively. Most of the transgenic Arabidopsis lines grew weakly compared with the wildtype Arabidopsis plants, and many seedlings died (Supplemental Figure 4). The transgene expression levels of six randomly selected transgenic $C y c 2 C L$-1-overexpressing (OE) and $C y c 2 C L-2-\mathrm{OE}$ Arabidopsis lines were analyzed in a qRT-PCR assay (Fig. 8). Of the six Cyc2CL-1$\mathrm{OE}$ lines, the highest and lowest $\mathrm{Cyc} 2 \mathrm{CL}-1$ expression levels were detected in lines $\# 35$ and $\# 5$, respectively. Among the six $C y c 2 C L-2-\mathrm{OE}$ lines, the highest and lowest $C y c 2 C L-2$ expression levels were detected in lines $\# 37$ and \#28, respectively (Fig. 8). The gene expression data confirmed that $C y c 2 C L-1$ and $C y c 2 C L-2$ were overexpressed in the transgenic Arabidopsis plants (Figs. 9 and 10). On the basis of $C y c 2 C L-1$ and $C y c 2 C L-2$ expression levels, $C y c 2 C L-1-\mathrm{OE}$ Arabidopsis lines \#35 and $\# 8$ as well as Cyc2CL-2-OE Arabidopsis lines \#37 and \#15 were selected for a subsequent phenotype analysis.
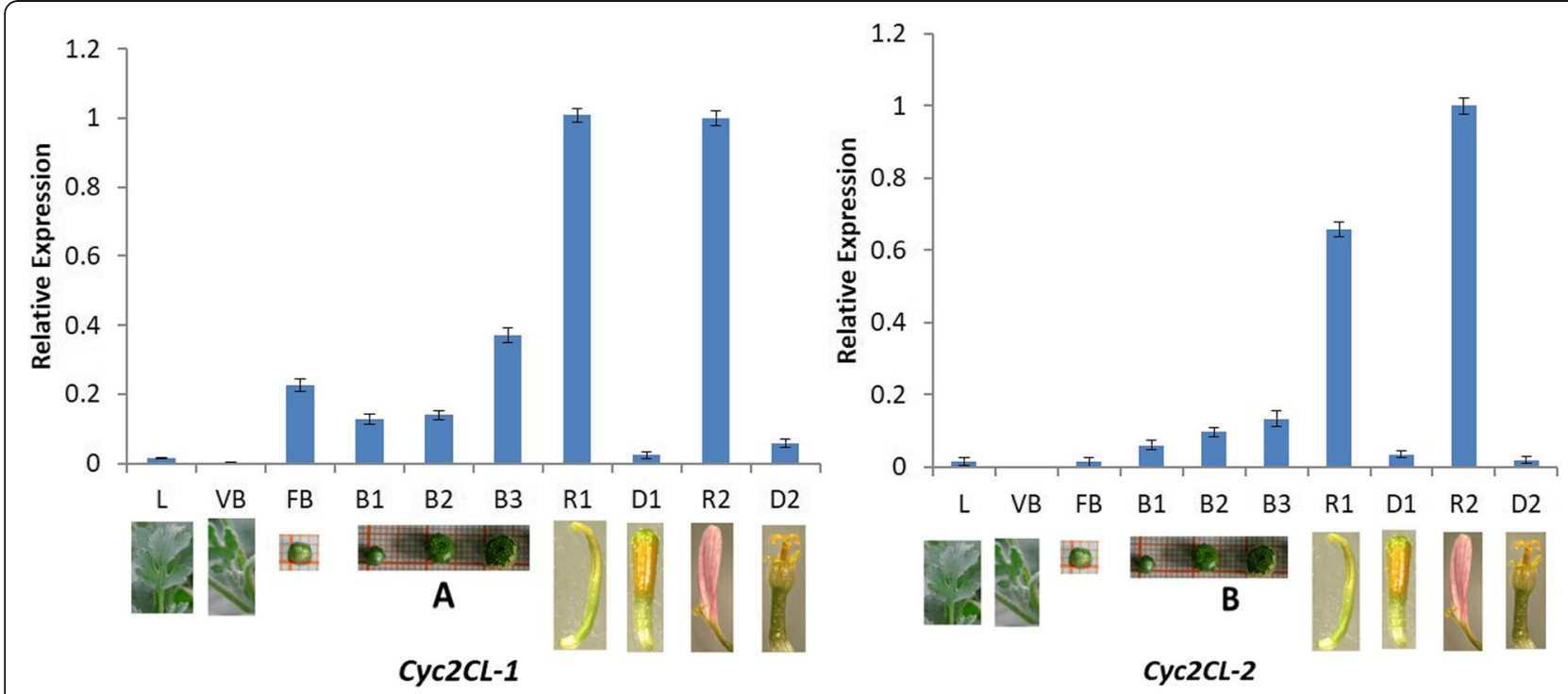

Fig. 5 Expression patterns of the C. morifolium CYC subfamily genes during various flower developmental stages. L: leaf, VB: vegetative bud, FB: flower bud, B1-B3: buds of three flower developmental stages, R1: ray floret during the early flowering stage, D1: disc floret during the early flowering stage, R2: ray floret during the full flowering stage, and D2: disc floret during the full flowering stage 


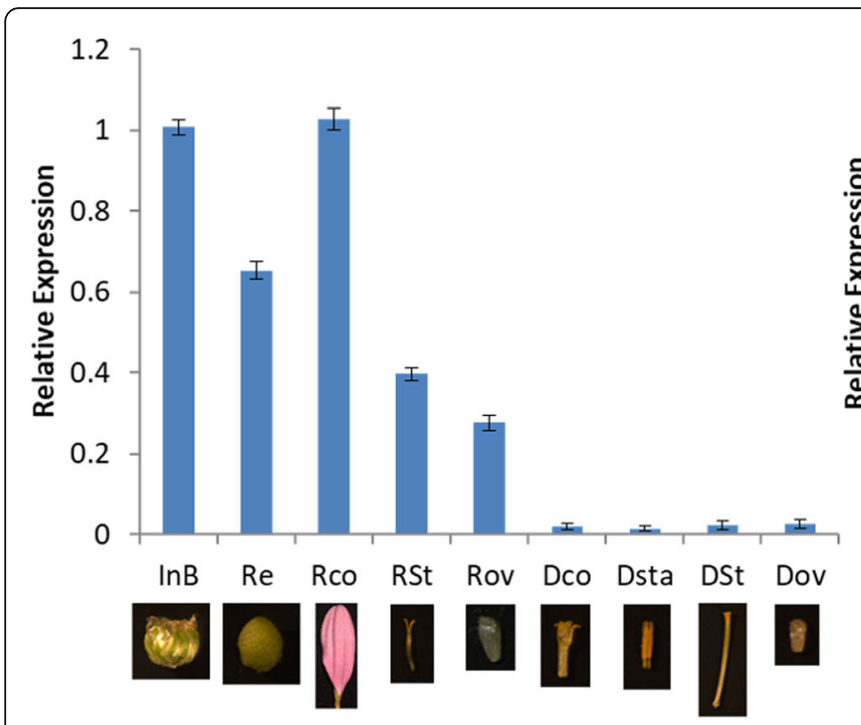

Cyc2CL-1

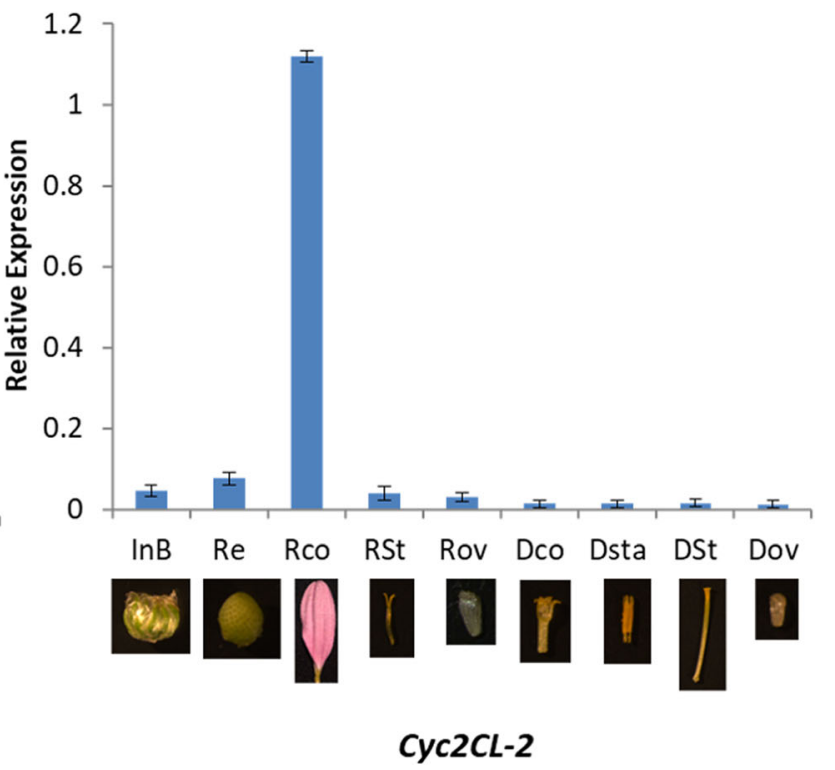

Fig. 6 Expression patterns of the C. morifolium CYC subfamily genes in different floral tissues. InB: involucral bract, Re: receptacle, RCo: ray floret corolla, RSt: ray floret stigma and style, ROv: ray floret ovary, DCo: disc floret corolla, DSta: disc floret stamen, DSt: disc floret stigma and style, and DOv: disc floret ovary

In the analyzed $C y c 2 C L-1-\mathrm{OE}$ and $C y c 2 C L-2-\mathrm{OE}$ Arabidopsis lines, the stamens were aborted and the petals were very short or absent, whereas the pistils and sepals were normal. Additionally, wild-type plants had six stamens, but the Cyc2CL-1-OE Arabidopsis plants produced only two stamens that were aborted and lacked pollen grains (Fig. 9e). The wild-type Arabidopsis plants had four petals, which was in contrast to the suppressed petal development in the Cyc2CL-1-OE Arabidopsis plants. In the examined $C y c 2 C L-2-\mathrm{OE}$ Arabidopsis lines, the petals grew, but were considerably shorter than the wild-type petals, suggesting that petal development was severely inhibited in the $C y c 2 C L-2-\mathrm{OE}$ Arabidopsis lines (Fig. 10e). Similar to the Cyc2CL-1-OE Arabidopsis lines, the $C y c 2 C L-2-\mathrm{OE}$ Arabidopsis lines produced two stamens that were aborted and lacked pollen grains. Additionally, normal pistils and sepals were detected in the Cyc2CL-2-OE Arabidopsis plants. Therefore, the Cyc2CL-1-OE and Cyc2CL-2-OE Arabidopsis lines were phenotypically similar. In both lines, the petals and stamens developed abnormally, and the stamens were aborted, resulting in a lack of pollen production. However, the pistils and sepals in the Cyc2CL-1-OE and Cyc2CL-2-OE Arabidopsis lines developed normally. To functionally characterize $C y c 2 C L-1$ and $C y c 2 C L-2$ regarding their inhibitory effects on native TCP genes, a qRT-PCR assay was completed to compare the TCP2, TCP3, TCP4, TCP10, and TCP24 expression levels between the wild-type Arabidopsis plants and the transgenic plants that were selected for the subsequent analysis of phenotypes [27]. The results indicated these genes were similarly expressed in the wild-type and transgenic Arabidopsis plants (Supplemental Figure 5). These results implied that Cyc2CL-1 and Cyc2CL-2 are important for stamen and petal development, but have no effect on pistil and sepal development in transgenic Arabidopsis plants.

\section{Discussion}

Discovery of the alternative splicing of $C y c 2 C L$ represents an important step toward revealing the subtle molecular mechanism regulating ray floret development in chrysanthemum

Genetic control of ray floret development in Asteraceae Previous studies involving G. hybrida, S. vulgaris, and $H$. annuus indicated that some $C Y C 2$ clade genes specifically expressed in ray florets determine the production of ray or disc florets. The regulatory mechanism underlying floral symmetry was originally characterized in A. majus. Two partially redundant $C Y C 2$ paralogs, $C Y C$ and $D I C H$, determine the dorsal identity of flowers and control the establishment of the zygomorphy (monosymmetry) in petal and stamen whorls [32, 33]. There has recently been considerable research focused on the regulatory functions of $C Y C$-like genes affecting the zygomorphic flowers in Asteraceae, Leguminosae, Gesneriaceae, and other plant families.

In Asteraceae, the $C Y C$-like genes are included in the $C Y C 1, C Y C 2$, and $C Y C 3$ subclades. Functional studies have confirmed that $C Y C$-like genes are important for controlling organ growth, both as positive and negative regulators involved in cell proliferation and/or expansion 


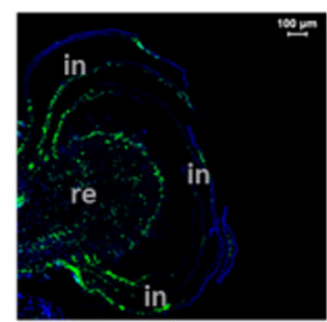

A

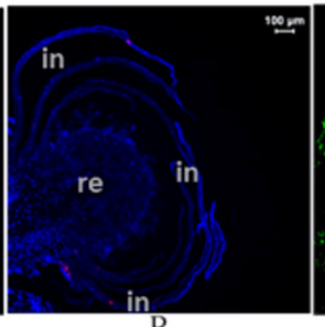

B

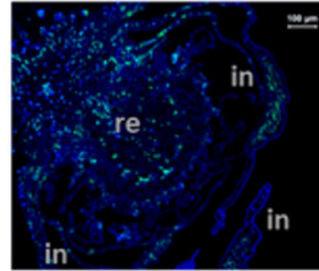

E

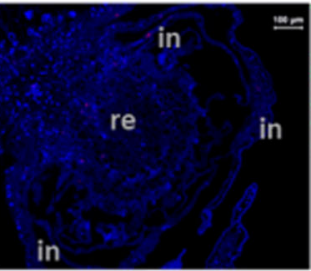

F

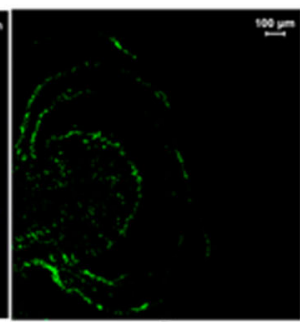

C

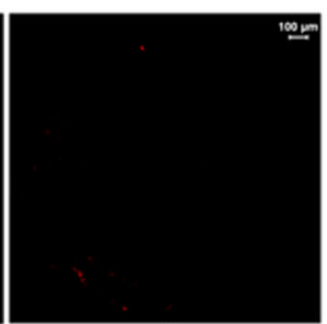

D

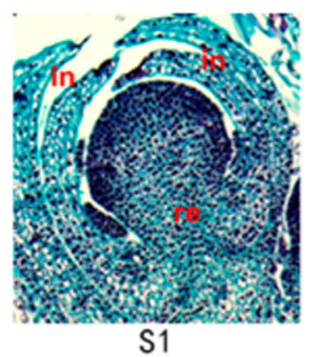

S1

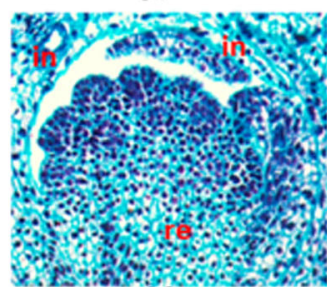

S2

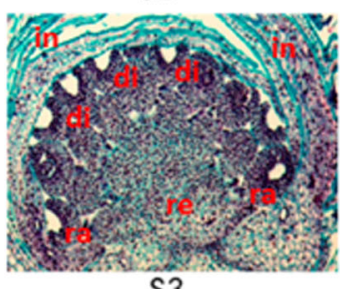

S3

Fig. 7 Fluorescence in situ hybridization images of labeled Cyc2CL-1 and Cyc2CL-2 RNA in inflorescences. a, c A FISH image of labeled Cyc2CL-1 RNA during the final involucre differentiation stage. b, d A FISH image of labeled Cyc2CL-2 RNA during the final involucre differentiation stage. S1: paraffin section image of the flower bud during the final involucre differentiation stage. e, $\mathbf{g}$ A FISH image of labeled Cyc2CL-1 RNA during the floret primordia differentiation stage. $\mathbf{f}, \mathbf{h}$ A FISH image of labeled Cyc2CL-2 RNA during the floret primordia differentiation stage. S2: paraffin section image of the flower bud during the floret primordia differentiation stage. i, $\mathbf{k}$ A FISH image of labeled Cyc2CL-1 RNA during the corolla formation stage. j, I A FISH image of labeled Cyc2CL-2 RNA during the corolla formation stage. S3: paraffin section image of the flower bud during the corolla formation stage. Inflorescence tissues were stained with DAPI (blue). The RNA probes for Cyc2CL-1 and Cyc2CL-2 are indicated in green and red, respectively. in: involucre; re: receptacle; ra: ray floret; and di: disc floret

$[6,9,10,21,46]$. Some studies have confirmed that CYC orthologs have a conserved role in controlling petal growth, and changes in their expressed domains determine whether zygomorphic or actinomorphic flowers are produced [2, 7, 22, 33, 43, 45, 48]. In S. vulgaris, $H$. annuus, and G. hybrida, CYC functions as a floral symmetry regulator, with a key role in determining floret identity (i.e., disc or ray florets) within the capitulum [2, 5, 43]. Duplication events considerably increased the diversity of the $C Y C 2$ clade genes within the Asteraceae lineage. Additionally, six, six, and five $C Y C 2$ clade genes have been identified in G. hybrida, S. vulgaris, and $H$. annuus, respectively. Some CYC2-like genes expressed exclusively in ray florets are essential for the formation of ray florets. For example, in $\mathrm{H}$. annuus, both $\mathrm{HaCYC2c}$ and $\mathrm{HaCYC} 2 \mathrm{~d}$ are specifically expressed in ray florets. In G. hybrida, of the CYC2-like genes, GhCYC2, GhCYC3, GhCYC4, GhCYC5, and GhCYC9 are expressed specifically in ray/trans florets $[2,5,24]$. Previous investigations revealed that the overexpression of $\mathrm{GhCYC2}$ in transgenic lines results in disc florets with ray floret features $[2,24,37]$. Similarly, in S. vulgaris, two CYC2 clade genes, $R A Y 1$ and $R A Y 2$, are also specifically expressed in ray florets, and both genes mediate the development of ray or disc florets [26]. Therefore, previous studies in $G$. hybrida, S. vulgaris, and $H$. annuus indicated that some $C Y C 2$ clade genes that are specifically expressed in ray florets determine the production of ray or disc florets. These genes include GhCYC2 in G. hybrida, $\mathrm{HaCYC} 2 d$ and $H a C Y C 2 c$ in $H$. annuus, and RAY1 and RAY2 in $S$. vulgaris.

\section{Identification of the $\mathrm{CYC} 2$ clade gene (Cyc2 $\mathrm{CL}$ ) and its two transcripts (Cyc2CL-1 and Cyc2CL-2) expressed in ray and disc florets}

In this study, one chrysanthemum CYC2-like gene $(\mathrm{Cyc} 2 \mathrm{CL})$ and its two alternatively spliced transcripts $(C y c 2 C L-1$ and $C y c 2 C L-2)$ were revealed. The AS of $C y c 2 C L$ was initiated during the floral bud differentiation stage in the apical buds. Gene expression analyses in a qRT-PCR assay proved that during the vegetative growth stage, $C y c 2 C L-1$ is expressed at low levels, whereas $C y c 2 C L-2$ is not expressed. Thus, $C y c 2 C L$ is not alternatively spliced during the vegetative growth stage. 


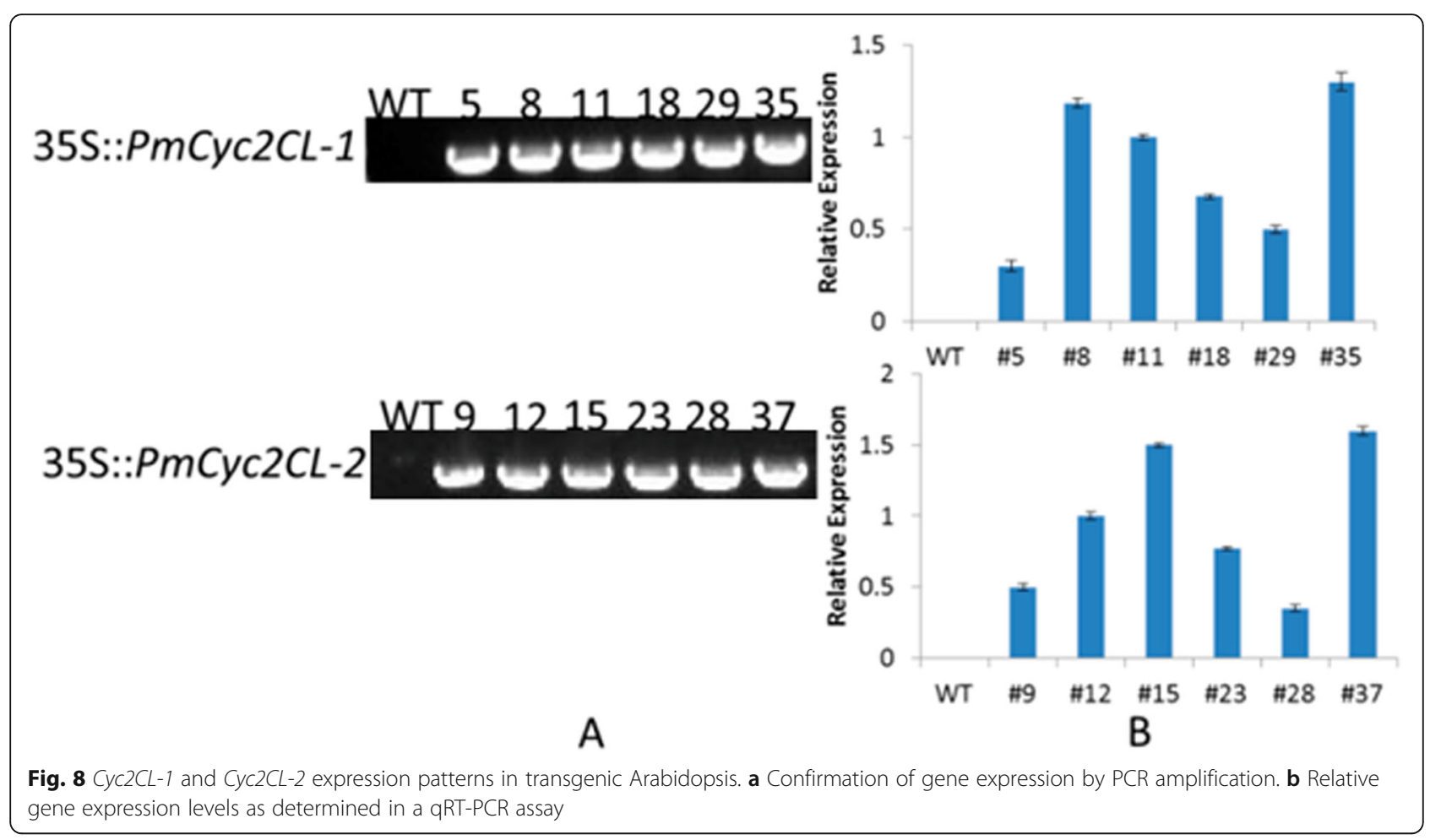

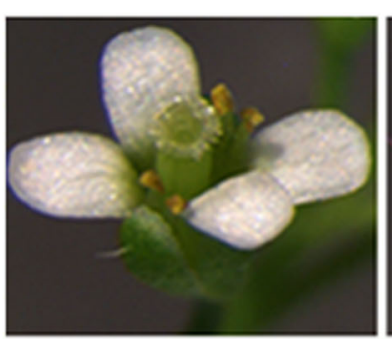

A

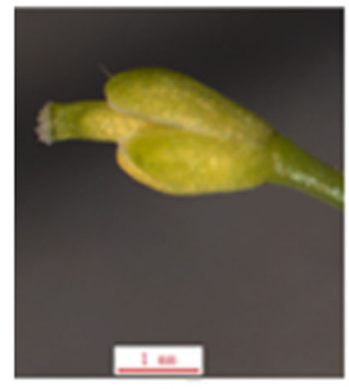

D

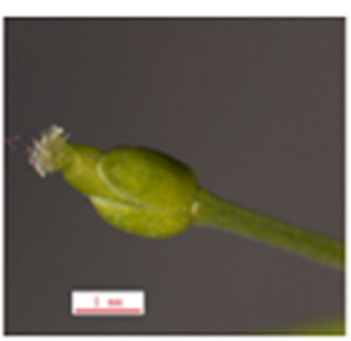

B

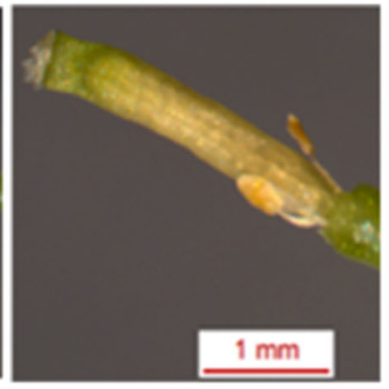

E

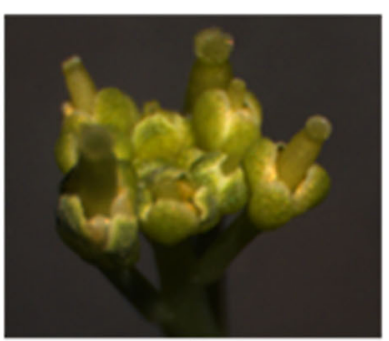

C

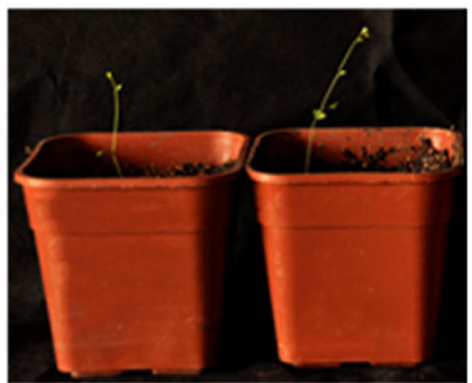

F

Fig. 9 Phenotypes of Arabidopsis plants overexpressing CyC2CL-1. a Wild-type flower. b Flower of an Arabidopsis plant overexpressing CyC2CL-1. The pistil and sepal grew normally. $\mathbf{c}$ Inflorescence of an Arabidopsis plant overexpressing Cyc2CL-1. The inflorescence had normal pistils and sepals, but the petals and stamens did not grow normally. d Flower of an Arabidopsis plant overexpressing Cyc2CL-1. Petal and stamen development was suppressed. e Flower of an Arabidopsis plant overexpressing Cyc2CL-1 after sepals were removed. Petals did not develop in this flower. The stigma was normal, but the stamens were aborted. f Arabidopsis plants overexpressing Cyc2CL-1 

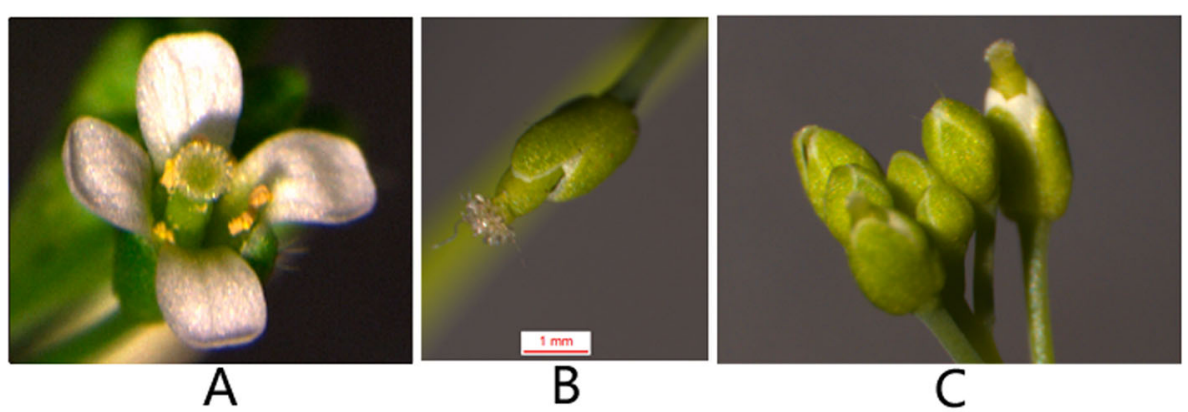

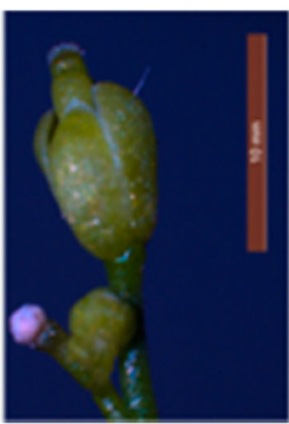

D

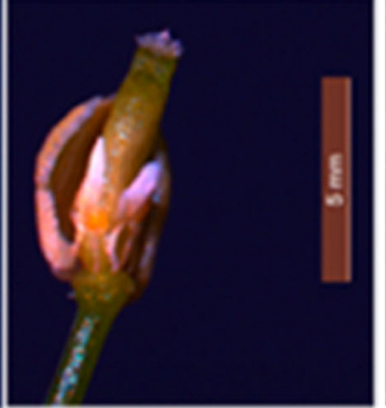

$\mathrm{E}$

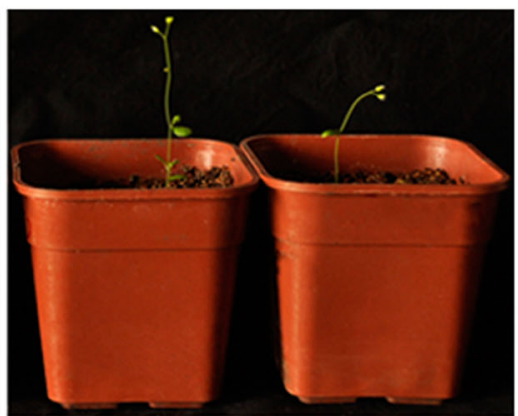

F

Fig. 10 Phenotypes of Arabidopsis plants overexpressing Cyc2CL-2. a Wild-type flower. b Flower of an Arabidopsis plant overexpressing Cyc2CL-2. The pistil and sepal grew normally. c Inflorescence of an Arabidopsis plant overexpressing Cyc2CL-2. The inflorescence had normal pistils and sepals, but the petals and stamens did not grow normally. d Flower of an Arabidopsis plant overexpressing Cyc2CL-2. Petal and stamen development was suppressed. e Flower of an Arabidopsis plant overexpressing Cyc2CL-2 after the sepals were removed. The petals were abnormally short. The stigma was normal, but the stamens were aborted. $\mathbf{f}$ Arabidopsis plants overexpressing Cyc2CL-2

However, the initiation of the floral bud differentiation stage resulted in up-regulated $C y c 2 C L-1$ expression levels as well as induced $C y c 2 C L-2$ expression, but at low levels. During the subsequent bud development stage, $C y c 2 C L-1$ expression was initially down-regulated, but then gradually increased as the buds developed (Fig. 5). Similarly, the $C y c 2 C L-2$ expression levels also increased as the buds developed. When the flowers bloomed, Cyc2CL-1 and Cyc2CL-2 were most highly expressed in the ray florets, whereas they were weakly expressed in the disc florets. Therefore, at some point during the floral bud differentiation stage, $C y c 2 C L$ was alternatively spliced to generate Cyc2CL-1 and Cyc2CL-2.

Chrysanthemum floral bud differentiation is believed to comprise the shoot-tip doming stage, the initial and final involucre differentiation stages, the initial and final floret primordia differentiation stages, and the corolla formation stage [30]. In this study, a FISH analysis of labeled $C y c 2 C L-1$ and $C y c 2 C L-2$ RNA was conducted to identify the particular developmental stage and tissue in which the AS of $C y c 2 C L$ was initiated to produce $C y c 2 C L-2$. We detected low $C y c 2 C L-2$ expression levels in the involucre tissue during the final involucre differentiation stage (Fig. 7b, d). In the subsequent floret primordia differentiation stage, Cyc2CL-2 was expressed in the receptacle and floret primordia in addition to the involucre tissue (Fig. $7 \mathrm{f}, \mathrm{h}$ ). During the corolla formation stage, $C y c 2 C L-2$ was highly expressed in the inflorescence tissue (Fig. 7j, l). Therefore, we determined that $C y c 2 C L-2$ is first produced in involucre tissue and then in other tissues during the floral bud differentiation stage.

Our qRT-PCR analysis confirmed that the AS of $C y c 2 C L$ was initiated in the floral bud differentiation stage, resulting in the production of $C y c 2 C L-2$. As the buds developed, the Cyc2CL-2 expression levels increased. These results were consistent with those of the FISH analysis. Additionally, Cyc2CL-1 was expressed in all inflorescence tissues and at higher levels than Cyc2CL-2. In sunflower, $\mathrm{HaCYC} 2 c$ is expressed in the corolla region of ray flowers and in the tubular flower reproductive organs, including the stamen, stigma, style, and ovary [43]. However, unlike the $C Y C 2$ clade genes specifically expressed in G. hybrida, $H$. annuus, and $S$. vulgaris ray florets, both $C y c 2 C L-1$ and $C y c 2 C L-2$ were weakly expressed in disc floret tissues.

\section{Both Cyc2CL-1 and Cyc2CL-2 may be important for regulating stamen and petal growth}

In chrysanthemum, the outer-layer ray florets vary regarding petal types and the inner-layer disc florets have diverse orientations. Additionally, the arrangement and combination of both floret types determine the daedal 
capitula types. Moreover, flower head types and petal types develop independently. Therefore, diverse petal types exist in specific types of flower heads. The complexity in the chrysanthemum petal and flower head types is indicative of a characteristic molecular mechanism involving $C Y C$ clade regulators. Huang et al. [22] cloned six $C Y C 2$ genes from two chrysanthemum cultivars and their $F_{1}$ progenies. They observed that in one CYC2 gene-overexpressing Chrysanthemum lavandulifolium line, some trans-like florets had short petals and abnormal stamens and were morphologically similar to ray florets [22]. Chen et al. [8] analyzed six $C Y C 2$-like genes in some Asteraceae species and evaluated the effects of $\mathrm{ClCYC2d}$ overexpression in C. lavandulifolium. They proved that the constitutive expression of ClCYC2d suppresses corolla growth during ray floret development [8]. Therefore, the $C Y C$ genes may be functionally diverse and the encoded proteins may interact to regulate the development of chrysanthemum ray florets.

Phenotypic analyses of the Cyc2CL-1-OE and Cyc2CL2-OE Arabidopsis lines verified that the stamens were aborted, and the petals were very short or absent, in contrast to the normal pistils and sepals. Alternative splicing can result in the production of multiple mRNAs from a single gene, thereby increasing the proteomic diversity of higher eukaryotes. It is also a vital mechanism for regulating gene expression during the growth and development of higher plants [25, 42]. The data presented herein imply that $C y c 2 C L-1$ and $C y c 2 C L-2$ likely play key regulatory roles related to stamen and petal growth.

The observed inhibitory effects of Cyc2CL-1 and Cyc2CL-2 expression on stamen and petal growth are consistent with the results of previous studies. In $A$. majus, both $C Y C$ and $D I C H$ are expressed in the dorsal domain of the young floral meristem, thereby retarding petal and stamen growth. At a later stage, CYC is expressed throughout the dorsal domain to facilitate petal lobe growth and inhibit stamen development [33]. In Primulina heterotricha, when flowers are dorsoventrally differentiated during floral development, two $C Y C 2$ clade genes, $C Y C 1 C$ and $C Y C 1 D$, are highly expressed in the dorsal petals and the dorsal/lateral stamens. Additionally, the substantial transcription of CYC1C in the lateral staminodes at the late development stage is related to the abortion of the dorsal and lateral stamens. Both $C Y C 1 C$ and $C Y C 1 D$ may regulate the decrease in the dorsal petal size and the abortion of the dorsal/lateral stamens [15, 47]. Fabio et al. confirmed that in $H$. annuus, TURF and CHRY are crucial for establishing the corolla symmetry of disc and ray flowers, but these genes also influence carpel and stamen development. Additionally, a loss-of-function mutation to the
CYC gene reportedly leads to hermaphroditic tubularlike ray florets replacing the normal sterile ray florets $[13,14,16,17,35]$. Another study indicated that CYClike genes help regulate stamen and carpel differentiation, likely via their association with the genes controlling the cell cycle and flower organ identity [15]. In G. hybrida, the ectopic overexpression of $\mathrm{GhCYC} 2$ disrupts stamen development and causes disc flowers to acquire enlarged and markedly fused petals [2].

Nag et al. [36] confirmed that the expression of TCP4 (i.e., a key target of miR319a) must be appropriately controlled to ensure normal petal and stamen development, with high TCP4 expression levels disrupting petal and stamen development in Arabidopsis. The ectopic expression of $C y c 2 C L-1$ and $C y c 2 C L-2$ similarly inhibits petal and stamen development. Therefore, the CYC and TCP target genes are likely conserved in chrysanthemum and Arabidopsis.

\section{The molecular mechanism underlying Cyc2CL-1 and Cyc2CL-2 functions remains to be revealed}

We identified a $C Y C 2$ clade gene $(C y c 2 C L)$ and its two transcripts $(C y c 2 C L-1$ and $C y c 2 C L-2)$ and assessed the effects of the ectopic expression of this gene in Arabidopsis to functionally characterize $C y c 2 C L-1$ and $C y c 2 C L-2$. However, the Cyc2CL-1-OE and Cyc2CL-2OE Arabidopsis lines were phenotypically similar, and the differences in the functions of the two transcripts were not obvious in the transgenic Arabidopsis plants, likely because of the substantial differences in the flower types and molecular mechanisms between chrysanthemums and Arabidopsis. Chrysanthemums have a capitulum consisting of bilateral (zygomorphic) ray florets and radial (actinomorphic) disc florets, whereas Arabidopsis plants produce only one type of radial flowers. Additionally, the gene regulatory mechanism is more complex in chrysanthemums than in Arabidopsis. The regulatory functions of $C y c 2 C L-1$ and $C y c 2 C L-2$ cannot be thoroughly analyzed based solely on the phenotypic changes in the transgenic Arabidopsis plants. Thus, we were unable to elucidate the precise molecular mechanism underlying $C y c 2 C L-1$ and $C y c 2 C L-2$ functions. Future investigations should examine the consequences of overexpressing and silencing $C y c 2 C L-1$ and $C y c 2 C L-2$ in chrysanthemum to clarify the regulatory functions of Cyc2CL-1 and Cyc2CL-2 related to ray floret development. Additionally, our qRT-PCR analysis revealed the Cyc2CL-1 and Cyc2CL-2 expression levels in the corolla region and reproductive organs of flowers, but the exact floral organ regions in which these genes are expressed should be determined via in situ RNA hybridization in future studies. Analyses of the proteins interacting with Cyc2CL-1 and Cyc2CL-2 as well as the downstream target genes should also be performed to provide new 
insights into the molecular mechanism controlling ray floret development in chrysanthemum.

\section{Methods}

Plant materials and RNA extraction

The individual plants used in this study were all derived by tissue culture from a hybrid of chrysanthemum varieties (i.e., C. morifolium 'Fenditan', which is a ground cover chrysanthemum variety). The plants were developed in our laboratory and were cultivated in a greenhouse at Beijing Forestry University $\left(116.3^{\circ} \mathrm{E}, 40.0^{\circ} \mathrm{N}\right)$ under long-day conditions (16-h light/8-h dark) for 180 days and then under short-day conditions (8-h light/16$\mathrm{h}$ dark) at $24 \pm 1{ }^{\circ} \mathrm{C}$. Under long-day conditions, approximately 100 vegetative buds were harvested between 9: 00-12:00 am. When the plants were first exposed to short-day conditions, about 100 apical buds were harvested between 9:00-12:00 am every week until visible floral buds formed, after which 100 buds were harvested between 9:00-12:00 am every week until the ray florets developed an observable color. Some harvested plant tissues were immediately placed in liquid nitrogen and stored at $-70^{\circ} \mathrm{C}$ for a subsequent RNA extraction step. Other plant tissues were treated and underwent a FISH analysis. Total RNA was extracted with the RNeasy Plant Mini Kit (Qiagen, Beijing, China). The quantity and quality of the extracted RNA were determined with the NanoDrop ND2000 spectrophotometer.

\section{Isolation of Chrysanthemum morifolium CYC2 genes and construction of phylogenetic trees}

Degenerate primers specific for $\mathrm{CYC} 2$ genes (Table 1) were designed based on the $C Y C 2$ homologs in the NCBI database $[2,5]$. Full-length cDNA sequences were obtained with the $3^{\prime}$ and 5' RACE cDNA amplification kits (Takara, Japan). Total DNA was extracted from harvested tissues with the DNAsecure Plant Kit (TianGen, Beijing, China). Total RNA was extracted from chrysanthemum capitula with the RNAprep Pure Kit (for plants) (TianGen, China). The target sequences were amplified by PCR, which was completed in a final reaction volume of $50 \mu \mathrm{l}$ comprising $2 \mu \mathrm{l} \mathrm{cDNA}$ (40 ng), $0.4 \mu \mathrm{l}$ Taq DNA polymerase (Promega), $1 \mu \mathrm{l}$ forward primer $(10 \mu \mathrm{M}), 1 \mu \mathrm{l}$ reverse primer $(10 \mu \mathrm{M}), 5 \mu \mathrm{l} 10 \times$ PCR buffer (Promega), $1 \mu \mathrm{l}$

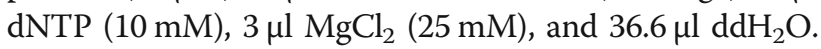
The PCR conditions were as follows: $94{ }^{\circ} \mathrm{C}$ for $5 \mathrm{~min}$; 30 cycles of $94{ }^{\circ} \mathrm{C}$ for $30 \mathrm{~s}, 58^{\circ} \mathrm{C}$ for $30 \mathrm{~s}$, and $72^{\circ} \mathrm{C}$ for $1 \mathrm{~min}$; $72^{\circ} \mathrm{C}$ for $10 \mathrm{~min}$. The amplified gene sequences were

Table 1 Degenerate primers used for amplifying C. morifolium CYC genes

\begin{tabular}{lll}
\hline Gene & Forward primer (5'-3') & Reverse primer (5'-3') \\
\hline CmCyc & ATGTTTTCYTCAAACCCYTTC & GTTTGCTTGCTTTGTCRAMCCTA \\
\hline
\end{tabular}

ligated to the pMD18-T vector and inserted into Escherichia coli DH5 $\alpha$ cells, after which the accuracy of the inserted fragments was verified by sequencing. The $C y c 2 C L-1$ and $C y c 2 C L-2$ coding sequences were deposited in the GenBank database (accession numbers: KP696775.1 and KP696776.1). We obtained CYC-like sequences from the NCBI database. The MEGA program (version 10) [28] was used to construct phylogenetic trees based on the maximum likelihood method involving the JTT matrixbased model [23].

\section{Gene expression analysis in a qRT-PCR assay}

The abundance of two transcripts (Cyc2CL-1 and Cyc2CL-2) in chrysanthemum flowers at different developmental stages was investigated in a qRT-PCR assay, which was completed with the PikoReal Real-Time PCR system (Thermo Fisher Scientific, Germany). To analyze the $C y c 2 C L-1$ and $C y c 2 C L-2$ expression patterns in the shoot apices and buds at different developmental stages, we sampled the vegetative buds (i.e., apical buds during the vegetative growth stage), flower buds (transection diameter of about $2 \mathrm{~mm}$ ), and buds at three flower developmental stages (first stage: bud transection diameter of about $3 \mathrm{~mm}$; second stage: bud transection diameter of about $5 \mathrm{~mm}$; and third stage: bud transection diameter of about $6-7 \mathrm{~mm}$ and colors were detectable in the outer ray florets; Fig. 5). To analyze the $C y c 2 C L-1$ and $C y c 2 C L-2$ expression patterns in ray and disc florets at different flower developmental stages, we collected ray and disc florets at the early and full flowering stages. In the early stage, colors were detectable in both ray and disc florets. During the full flowering stage, ray and disc florets had bloomed. Furthermore, to analyze the $C y c 2 C L-1$ and $C y c 2 C L-2$ expression patterns in different floral tissues, we collected the involucral bract, receptacle, corolla, and pistil (stigma, style, and ovary) of ray florets as well as the corolla, stamen, and pistil (stigma, style, and ovary) of disc florets (Fig. 6). The leaves of wild-type and transgenic Arabidopsis plants were collected to analyze the $C Y C 2$ and $T C P$ gene expression levels. We collected three biological replicates for each tissue. The qRT-PCR was completed with SYBR Premix Ex Taq (TaKaRa) and the PikoReal RealTime PCR system (Thermo Fisher Scientific). Each reaction was prepared in a total volume of $20 \mu \mathrm{l}$ containing $2 \mu \mathrm{l}$ first-strand cDNA as the template. The qRT-PCR conditions were as follows: $95^{\circ} \mathrm{C}$ for $30 \mathrm{~s}$; 40 cycles of $95^{\circ} \mathrm{C}$ for $5 \mathrm{~s}$, the optimal annealing temperature for $30 \mathrm{~s}$, and $60^{\circ} \mathrm{C}$ for $30 \mathrm{~s}$. The C. morifolium protein phosphatase $2 \mathrm{~A}$ gene (PP2Acs) was used as the reference gene. Details regarding the qRT-PCR primers are provided in Table 2. The qRT-PCR primers specific for Arabidopsis TCP genes are listed in Supplemental Table 1. The qRT-PCR assay was completed with three biological replicates, with samples analyzed in triplicate in each replicate. 
Table 2 Details regarding the qRT-PCR primers specific for $C$. morifolium genes

\begin{tabular}{lll}
\hline Gene & Forward primer $\left(\mathbf{5}^{\prime}-\mathbf{3}^{\prime}\right)$ & Reverse primer $\left(\mathbf{5}^{\prime} \mathbf{-} \mathbf{3}^{\prime}\right)$ \\
\hline PP2ACS & ATCAGAACAGGAGGTCAGGG & TAATTGTATCGGGGCACTT \\
Cyc2CL-1 & CCATGGCAAGAGCGAGAGCAC & GATATAGGCGGATAGCATAC \\
Cyc2CL-2 & GCTGATGATGATTTGAAGACA & GTCCAGGTCCACCATTAATTC \\
\hline
\end{tabular}

\section{Vector construction and Arabidopsis transformation}

Full-length $C y c 2 C L-1$ and $C y c 2 C L-2$ cDNA sequences were amplified by a PCR with gene-specific primers (Table 3). The amplicons were inserted into the pGEM$\mathrm{T}$ vector (Promega), after which the accuracy of the inserted fragments was confirmed by sequencing. The Cyc2CL-1 and Cyc2CL-2 sequences were then digested with restriction enzymes and subcloned into pCAMBIA1304 and modified pCAMBIA1304 vectors. The resulting plasmids were inserted into Agrobacterium tumefaciens strain EHA105 cells, which were then used to transform Arabidopsis (Col-0) cells according to a floral-dip method [11]. The putative transgenic lines were screened on Murashige and Skoog medium containing $50 \mathrm{mg} / \mathrm{l}$ hygromycin. The hygromycin-resistant seedlings $\left(\mathrm{T}_{0}\right.$ generation) were transferred to soil after 14 days and grown at $21-23^{\circ} \mathrm{C}$ under long-day conditions. The $\mathrm{T}_{3}$ generation plants were subsequently analyzed. Col-0 seeds were obtained from the Arabidopsis Biological Resource Center (www.arabidopsis.org).

\section{Fluorescence in situ hybridization}

The expression of $C y c 2 C L-1$ and $C y c 2 C L-2$ in shoot apices and buds at different developmental stages was analyzed by FISH. We designed LNA-based probes to target the mature $C y c 2 C L-1$ and $C y c 2 C L-2$ mRNA sequences (Table 4). Sense probes were used as the FISH assay negative controls (Supplemental Table 2). Shoot apices and buds collected at different developmental stages were fixed with a $4 \%$ paraformaldehyde solution for 30 min, after which frozen tissue sections were prepared. The fixed slides were washed twice with PBS, treated with proteinase $\mathrm{K}$ at $37^{\circ} \mathrm{C}$ for $10 \mathrm{~min}$, and then dehydrated in 70,85 , and $100 \%$ ethanol for 5 min each. After a denaturing treatment at $78{ }^{\circ} \mathrm{C}$ for $5 \mathrm{~min}$, the probes were added to the slides and allowed to hybridize overnight at $42^{\circ} \mathrm{C}$ under humid conditions. The slides were washed with $50 \%$ formamide $/ 2 \times \mathrm{SSC}$ at $43{ }^{\circ} \mathrm{C}$ and then

Table 3 Gene-specific primers used for the PCR amplification of full-length Cyc2CL-1 and CyC2CL-2 CDNA sequences

\begin{tabular}{lll}
\hline Gene & Forward primer (5'-3') & Reverse primer (5'-3') \\
\hline Cyc2CL-1 & ACTAGTATGTTTCTTCAAACC & GGTGACCCAACTAGATATAG \\
& CCTITCCAG & GCGGAATAGC \\
CyC2CL-2 & ACTAGTATGTTTCTTCAAACC & GGTGACCGACTAACAACATC \\
& CCTITCCAG & AGTCCAGGTC \\
\hline
\end{tabular}

Table 4 Gene-specific probe sequences for the fluorescence in situ hybridization of Cyc2CL-1 and Cyc2CL-2

\begin{tabular}{ll}
\hline Gene & Probes sequence $\left(\mathbf{5}^{\prime} \mathbf{-} \mathbf{3}^{\prime} \mathbf{)}\right.$ \\
\hline Cyc2CL- & GTAT GCTAT TCCGC CTATA TCTAG \\
1 & \\
Cyc2CL- & CAGTACTGACCACTTCTGGGCAGGAATTAATGGTGGACCTGG \\
2 & ACTGATGTTGTAA \\
\hline
\end{tabular}

with $2 \times$ SSC at room temperature to eliminate the nonspecific and repetitive RNA hybridizations. Finally, the slides were counterstained with DAPI (Sigma) for 10 min and then observed with a Zeiss LSM 700 Meta confocal microscope.

\section{Supplementary Information}

The online version contains supplementary material available at https://doi. org/10.1186/s12870-021-02884-z.

Additional file 1.

\section{Abbreviation}

AS: Alternative splicing

\section{Acknowledgments}

We acknowledge Professor Conglin Huang for his invaluable help and support in our research. We thank Liwen Bianji, Edanz Editing China (www. liwenbianji.cn/ac) for editing the English text of a draft of this manuscript.

\section{Authors' contributions}

$H L$ and $Q X Z$ designed the whole experiments; $H L$ conducted the experiments and wrote the manuscript; H L, M S, HT P, TR C and J W analyzed the data. All authors read and approved the final manuscript.

\section{Funding}

This research was funded by Special Fund for Beijing Common Construction Project, Beijing Natural Science Foundation (6194033) and Natural Science Foundation of the Beijing Academy of Agriculture and Forestry Sciences (QNJJ201817). All the funding bodies didn't participate in the design of the study and collection, analysis, and interpretation of data and writing the manuscript

Availability of data and materials

The datasets generated and/or analysed during the current study are available in the GenBank repository at NCBI (accession numbers: KP696775.1 and KP696776.1).

Ethics approval and consent to participate

Not applicable.

Consent for publication

Not applicable.

\section{Competing interests}

The authors declare that they have no competing interests.

Received: 30 July 2020 Accepted: 9 February 2021

Published online: 19 February 2021

\section{References}

1. Berger BA, Thompson V, Lim A, Ricigliano V, Howarth DG. Elaboration of bilateral symmetry across Knautia macedonica capitula related to changes in ventral petal expression of CYCLOIDEA -like genes. EvoDevo. 2016;7:1-10.

2. Broholm SK, Sari TH, Laitinen RAE, Albert VA, Teeri TH, Paula E. A TCP domain transcription factor controls flower type specification along the 
radial axis of the Gerbera (Asteraceae) inflorescence. Proc Natl Acad Sci USA. 2008:105:9117-22.

3. Carlson SE, Howarth DG, Donoghue MJ. Diversification of CYCLOIDEA-like genes in Dipsacaceae (Dipsacales): implications for the evolution of capitulum inflorescences. BMC Evol Biol. 2011;11:1-13.

4. Carvalho RF, Feijão CV, Duque P. On the physiological significance of alternative splicing events in higher plants. Protoplasma. 2013;250:639-50.

5. Chapman MA, Leebens-Mack JH, Burke JM. Positive selection and expression divergence following gene duplication in the sunflower CYCLOIDEA gene family. Mol Biol Evol. 2008;25:1260-73.

6. Chapman MA, Shunxue T, Rthe D, Savithri N, Hunter S, Barb JG, Knapp SJ, Burke JM. Genetic analysis of floral symmetry in van Gogh's sunflowers reveals independent recruitment of CYCLOIDEA genes in the Asteraceae. PLoS Genet. 2012a;8:e1002628.

7. Chapman MA, Tang S, Draeger D, Nambeesan S, Shaffer H, Barb JG, Knapp SJ, Burke JM. Genetic analysis of floral symmetry in van Gogh's sunflowers reveals independent recruitment of CYCLOIDEA genes in the Asteraceae. PLoS Genet. 2012b;8:e1002628.

8. Chen J, Shen C-Z, Guo Y, Rao G-Y. Patterning the Asteraceae Capitulum: duplications and differential expression of the flower symmetry CYC2-like genes. Front Plant Sci. 2018;9:551 https://doi.org/10.3389/fpls.2018.00551.

9. Citerne HL, Le Guilloux M, Sannier J, Nadot S, Damerval C. Combining phylogenetic and syntenic analyses for understanding the evolution of TCP ECE genes in eudicots. PLoS One. 2013;8:e74803.

10. Citerne HL, Reyes E, Le Guilloux M, Delannoy E, Simonnet F, Sauquet $H$, Weston PH, Nadot S, Damerval C. Characterization of CYCLOIDEA-like genes in Proteaceae, a basal eudicot family with multiple shifts in floral symmetry. Ann Bot. 2017;119:367-78.

11. Clough SJ, Bent AF. Floral dip: a simplified method forAgrobacterium-mediated transformation ofArabidopsis thaliana. Plant J Cell Mol Biol. 1998;16:735-43.

12. Dilcher D. Toward a new synthesis : major evolutionary trends in the angiosperm fossil flower. Proc Natl Acad Sci USA. 2000;97:7030-6.

13. Fabio B, Marco F, Maurizio T, Daniele B, Claudio P. Mutations of corolla symmetry affect carpel and stamen development in Helianthus annuus. Can J Bot. 2005;83:1065-72.

14. Fambrini M, Michelotti V, Pugliesi C. The unstable tubular ray flower allele of sunflower: inheritance of the reversion to wild-type. Plant Breed. 2007; 126(5):548-50

15. Fambrini M, Pugliesi C. CYCLOIDEA 2 clade genes: key players in the control of floral symmetry, inflorescence architecture, and reproductive organ development. Plant Mol Biol Report. 2017;35:20-36 https://doi.org/10.1007/s11105-016-1005-z

16. Fambrini M, Salvini M. Pugliesi C. A transposon-mediate inactivation of a CYCLOIDEA-like gene originates polysymmetric and androgynous ray flowers in Helianthus annuus[J]. Genetica. 2011:139(11-12):1521-9.

17. Fambrini M, Salvini M, Basile A, Pugliesi C. Transposon-dependent induction of Vincent van Gogh's sunflowers: exceptions revealed. Genesis. 2014;52(4): 315-27 https://doi.org/10.1002/dvg.22743.

18. Garcês HM, Spencer VM, Kim M. Control of floret symmetry by RAY3, SVDIV1B and SVRAD in the capitulum of Senecio vulgaris. Plant Physiol. 2016;171:2055-68.

19. Gu C, Chen S, Liu Z, Shan H, Luo H, Guan Z, Chen F. Reference gene selection for quantitative real-time PCR in Chrysanthemum subjected to biotic and abiotic stress. Mol Biotechnol. 2011;49:192-7.

20. Hileman LC. Bilateral flower symmetry--how, when and why? Curr Opin Plant Biol. 2014;17:146-52.

21. Howarth DG, Donoghue MJ. Phylogenetic analysis of the "ECE" (CYC/TB1) clade reveals duplications predating the core eudicots. Proc Natl Acad Sci USA. 2006;103:9101-6.

22. Huang D, Li X, Sun M, Zhang T, Pan H, Cheng T, Wang J, Zhang Q. Identification and characterization of CYC-like genes in regulation of ray floret development in Chrysanthemum morifolium. Front Plant Sci. 2016; https://doi.org/10.3389/fpls.2016.01633.

23. Jones DT, Taylor WR, Thornton JM. The rapid generation of mutation data matrices from protein sequences. Comput Appl Biosci. 1992;8(3):275-82.

24. Juntheikki-Palovaara I, Tähtiharju S, Lan T, Broholm SK, Rijpkema AS, Ruonala R, Kale L, Albert VA, Teeri TH, Elomaa P. Functional diversification of duplicated CYC2 clade genes in regulation of inflorescence development in Gerbera hybrida (Asteraceae). Plant J. 2014;79:783-96.

25. Kalyna M, Simpson CG, Syed NH, Lewandowska D, Marquez Y, Kusenda B, Marshall J, Fuller J, Cardle L, Mcnicol J. Alternative splicing and nonsensemediated decay modulate expression of important regulatory genes in Arabidopsis. Nucleic Acids Res. 2012;40:2454-69.
26. Kim M, Cui ML, Cubas P, Gillies A, Lee K, Chapman MA, Abbott RJ, Coen E. Regulatory genes control a key morphological and ecological trait transferred between species. Science. 2008;322:1116-9.

27. Koyama T, Ohme-Takagi M, Sato F. Generation of serrated and wavy petals by inhibition of the activity of tcp transcription factors in arabidopsis thaliana. Plant Signal Behav. 2011;6(5):697.

28. Kumar S, Stecher G, Li M, Knyaz C, Tamura KMEGAX. molecular evolutionary genetics analysis across computing platforms. Mol Biol Evol. 2018;35(6): 1547-9 https://doi.org/10.1093/molbev/msy096.

29. Laitinen RA, Broholm S, Albert VA, Teeri TH, Elomaa P. Patterns of MADS-box gene expression mark flower-type development in Gerbera hybrida (Asteraceae). BMC Plant Biol. 2006;6:11.

30. Li FT, Chen SM, Chen FD, Fang WM, Liu ZL, Zhang F. Histological structure observation on the floral development of anemone type chrysanthemum. Acta Horticulturae Sin. 2010;37:1961-8.

31. Liu H, Sun M, Du D, Pan H, Cheng T, Wang J, Zhang Q, Gao Y. Wholetranscriptome analysis of differentially expressed genes in the ray florets and disc florets of Chrysanthemum morifolium. BMC Genomics. 2016;17:1-17.

32. Luo D, Carpenter R, Copsey L, Vincent C, Clark J, Coen E. Control oforgan asymmetry in flowers of Antirrhinum. Cell. 1999;99:367-76.

33. Luo D, Carpenter R, Vincent C, Copsey L, Coen E. Origin of floral asymmetry in Antirrhinum. Nature. 1996:383:794-9.

34. Minsung K, Min-Long C, Pilar C, Amanda G, Karen L, Chapman MA, Abbott RJ, Enrico C. Regulatory genes control a key morphological and ecological trait transferred between species. Science. 2008;322:1116-9.

35. Mizzotti C, Fambrini M, Caporali E, Masiero S, Pugliesi CA. CYCLOIDEA-like gene mutationin sunflower determines anunusual floret type able to produce filled achenes at the periphery of the pseudanthium. Botany. 2015;93:171-81.

36. Nag A, King S, Jack T. miR319a targeting of TCP4 is critical for petal growth and development in Arabidopsis. Proc Natl Acad Sci. 2009;106(52):22534-9 https://doi.org/10.1073/pnas.0908718106.

37. Preston JC, Hileman LC. Developmental genetics of floral symmetry evolution. Trends Plant Sci. 2009;14:147-54.

38. Pucker B, Brockington SF. Genome-wide analyses supported by rna-seq reveal non-canonical splice sites in plant genomes. BMC Genomics. 2018;19(1):980.

39. Reddy ASN, Marquez Y, Kalyna M, Barta A. Complexity of the alternative splicing landscape in plants. Plant Cell. 2013;25:3657.

40. Silva JAT. Chrysanthemum: advances in tissue culture, cryopresenvation, postharvest technology, genetics and transgenic biotechnology. Biotechnol Adv. 2003;21:715-66.

41. Stuessy TF, Urtubey E. Phylogenetic implications of corolla morphology in subfamily Barnadesioideae (Asteraceae). Flora. 2006;201(5):340-52 https:// doi.org/10.1016/j.flora.2005.07.009.

42. Syed NH, Kalyna M, Marquez Y, Barta A, Brown JWS. Alternative splicing in plants - coming of age. Trends Plant Sci. 2012;17:616-23.

43. Tähtiharju S, Rijpkema AS, Vetterli A, Albert VA, Teeri TH, Elomaa P. Evolution and diversification of the $\mathrm{CYC} / \mathrm{TB} 1$ gene family in Asteraceae-a comparative study in Gerbera (Mutisieae) and sunflower (Heliantheae). Mol Biol Evol. 2012;29:1155-66.

44. Torices R, Méndez M, Gómez JM. Where do monomorphic sexual systems fit in the evolution of dioecy? Insights from the largest family of angiosperms. New Phytol. 2011;190:234-48.

45. Xia Y, Hong-Bo P, Bo-Ling L, Zhi-ling Q, Qiu G, Lai W, Yang D, Yin-Zheng W. Evolution of double positive autoregulatory feedback loops in CYCLOIDEA2 clade genes is associated with the origin of floral zygomorphy. Plant Cell. 2012;24:1834-47.

46. Yafei Z, Kai P, Barbara DA, Oriane H, Annette B, Paula E. Evolutionary diversification of cyc/tb1-like tcp homologs and their recruitment for the control of branching and floral morphology in papaveraceae (basal eudicots). New Phytol. 2018;220(1):317-31.

47. Yang X, Pang H-B, Liu B-L, Qiu Z-J, Gao Q, Wei L, Dong Y, Wang Y-Z. Evolution of double positive autoregulatory feedback loops in CYC2 clade genes is associated with the origin of floral zygomorphy. Plant Cell. 2012;24:1834-47.

48. Yang X, Zhao X, Li C, Liu J, Qiu Z, Dong Y, Wang Y. Distinct regulatory changes underlying differential expression of TEOSINTE BRANCHED1CYCLOIDEA-PROLIFERATING CELL FACTOR genes associated with petal variations in zygomorphic flowers of Petrocosmea spp. of the family Gesneriaceae. Plant Physiol. 2015;169:2138-51.

\section{Publisher's Note}

Springer Nature remains neutral with regard to jurisdictional claims in published maps and institutional affiliations. 